\title{
The McKenna reaction - avoiding side reactions in phosphonate deprotection
}

\author{
Katarzyna Justyna ${ }^{1}$, Joanna Małolepsza ${ }^{1}$, Damian Kusy ${ }^{1}$, Waldemar Maniukiewicz ${ }^{2}$ \\ and Katarzyna M. Błażewska*1
}

\author{
Full Research Paper \\ Address: \\ ${ }^{1}$ Institute of Organic Chemistry, Faculty of Chemistry, Lodz University \\ of Technology, Zeromskiego St. 116, 90-924 Lodz, Poland and \\ ${ }^{2}$ Institute of General and Ecological Chemistry, Faculty of Chemistry, \\ Lodz University of Technology, Zeromskiego St. 116, 90-924 Lodz, \\ Poland \\ Email: \\ Katarzyna M. Błażewska* - katarzyna.blazewska@p.lodz.pl \\ * Corresponding author \\ Keywords: \\ bromotrimethylsilane; McKenna reaction; organophosphorus acid; \\ oxazole; phosphonate ester
}

\author{
Beilstein J. Org. Chem. 2020, 16, 1436-1446. \\ doi:10.3762/bjoc.16.119 \\ Received: 21 January 2020 \\ Accepted: 29 May 2020 \\ Published: 23 June 2020 \\ Associate Editor: B. Stoltz \\ (C) 2020 Justyna et al.; licensee Beilstein-Institut. \\ License and terms: see end of document.
}

\begin{abstract}
The McKenna reaction is a well-known and popular method for the efficient and mild synthesis of organophosphorus acids. Bromotrimethylsilane (BTMS) is the main reagent in this reaction, which transforms dialkyl phosphonate esters into bis(trimethylsilyl)esters, which are then easily converted into the target acids. However, the versatile character of the McKenna reaction is not always used to its full extent, due to formation of side products. Herein, demonstrated by using model examples we have not only analyzed the typical side processes accompanying the McKenna reaction, but also uncovered new ones. Further, we discovered that some commonly recommended precautions did not always circumvent the side reactions. The proposed results and recommendations may facilitate the synthesis of phosphonic acids.
\end{abstract}

\section{Introduction}

The McKenna reaction is a tool for the synthesis of organophosphorus acids from their esters and known for over 40 years $[1,2]$. The importance of this class of compounds is widely recognized as phosphorus acids and esters are prevailing in nature $[3,4]$, and the compounds found wide applications as therapeutics [5,6], probes [7] or in materials science [8].

The McKenna reaction involves two steps: In the first step an alkyl ester is transformed into the corresponding trimethylsilyl ester [9], which is cleaved in the second step, upon solvolysis, forming the final product (Scheme 1). Bromotrimethylsilane (BTMS) is the main reagent in this reaction and is also known for its ability to cleave lactones, epoxides, acetals, and ethers [10]. BTMS also acted as a brominating agent and reagent for the formation of silyl enol ethers [10]. However, these reactions often required higher temperatures (up to $100^{\circ} \mathrm{C}$ ) or were applicable to only certain types of functional groups, such as methoxymethyl ethers [10]. Still, BTMS, due to its balanced 


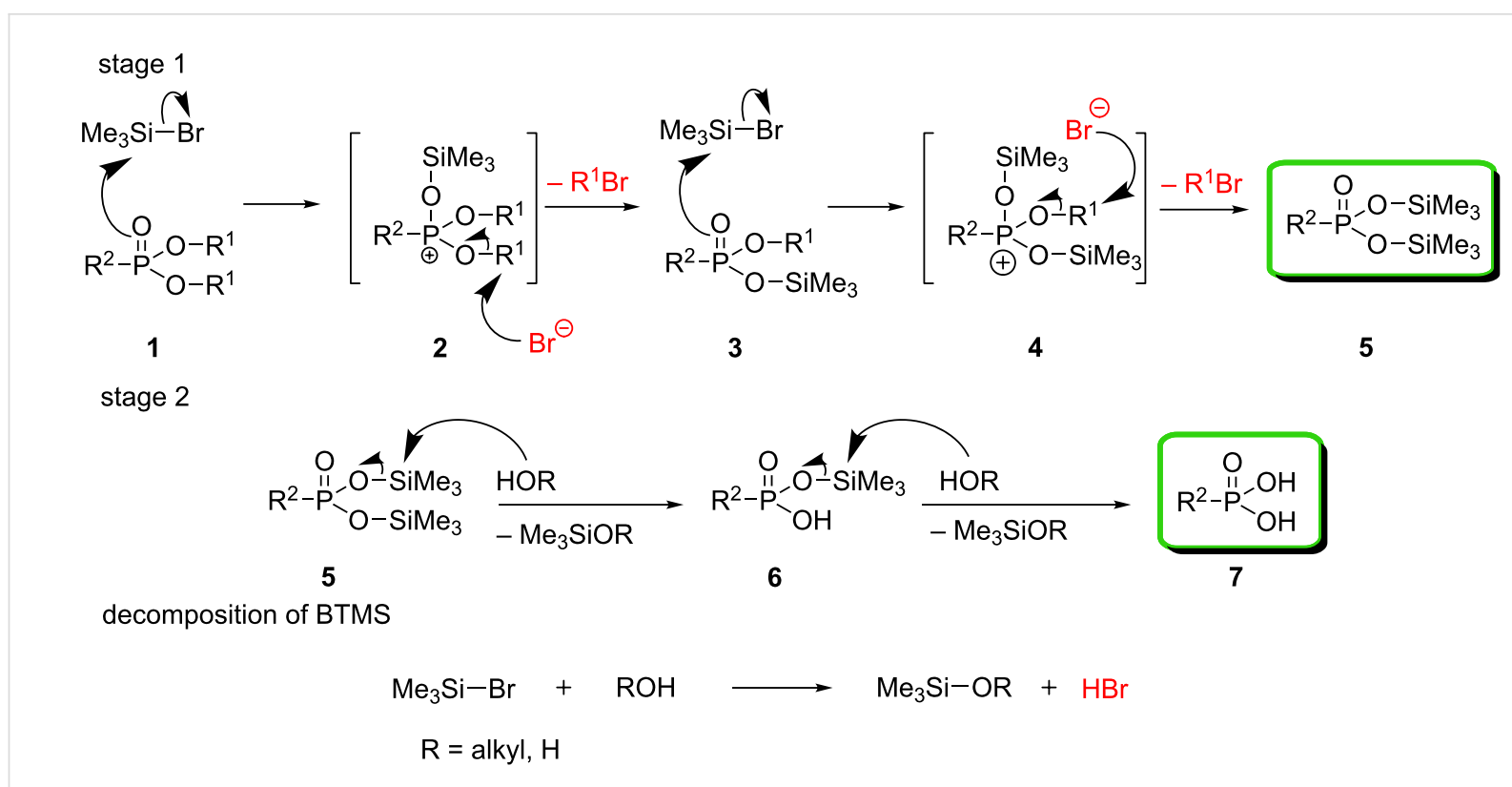

Scheme 1: Schematic overview of the McKenna reaction including the decomposition of BTMS in protic solvents. The desired products of the McKenna reaction are presented in green and the reagents that potentially are responsible for side reactions are presented in red.

effectiveness and high chemoselectivity, is the reagent of choice for phosphonate ester cleavage, compared with its more and less reactive analogs, iodotrimethylsilane (ITMS) [11,12] and chlorotrimethylsilane (CTMS) [13], respectively.

While being one of the most popular methods for the deprotection of organophosphorus esters, the McKenna reaction may be accompanied by side reactions such as the cleavage of tert-butyl carboxyester, $[14,15]$ or other ester groups [16], as well as the formation of decomposition products [17-20]. Instead of focusing only on the experiments that "did work", we decided to follow an alternative strategy recommended by Björnmalm and Caruso [21] and to report failures, as a tool to facilitate and accelerate new studies requiring the synthesis of phosphonic acids. To the best of our knowledge, this is the first systematic study on side reactions accompanying the McKenna reaction.

It is important to distinguish the side reactions, which originate from BTMS itself, and those resulting from not having taken appropriate precautions during the subsequent solvolysis step. By being alerted to the water-sensitive character of BTMS and the formation of the alkylating agent alkyl bromide (Scheme 1), side reactions occurring during the silylation step could be usually prevented. On the other hand, the side reactions during the solvolysis step are usually obviated by the use of a buffer or weak base, which neutralize the final organophosphorus acids. Herein we mainly addressed the problems related to the silylation step of the McKenna reaction. To this end, we used model compounds from our previous work, analyzed the possible side reactions, and proposed solutions in order to minimize or prevent the unwanted processes. We also showed that tertiary amines, that are commonly used as additives to prevent these side reactions, should be used with caution, as they themselves may promote side reactions.

\section{Results and Discussion}

Our objective was to subject selected bifunctional compounds to the McKenna reaction conditions. In order to simplify the design of the study, in most cases the reaction mixture contained two model compounds, with one representing the phosphonate, and the other containing a functional group, which could undergo a side reaction under the reaction conditions.

As the first class of compounds, representing the phosphoryl group, we used phosphonates 8 and 9 (Figure 1). As the second class of model compounds, which should remain intact under McKenna's reaction conditions, we synthesized analogs 9, and 10-13 (Figure 1). Among the representative functional groups, we selected compounds comprising a triple (10) and a double (11) bond, both susceptible to $\mathrm{HBr}$ addition. Compounds 12 and 9a-d were selected for studying the possibility of an $\mathrm{N}$-alkylation by alkyl bromide, formed during the silylation step. Finally, compound $\mathbf{1 3}$ was included to study the possibility of a chlorine for bromine exchange reaction. The phosphonocarboxylates 8 and 9 were used to explore whether the carboxyester group could be cleaved upon exposure to BTMS. All model compounds were prepared according to literature procedures and thoroughly dried before use [22-25]. 


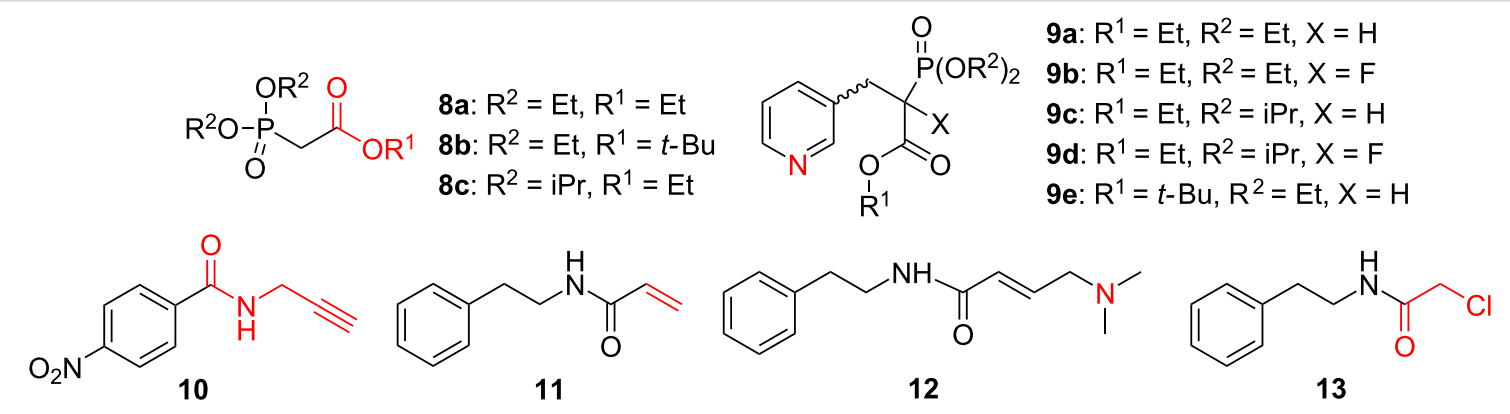

Figure 1: The model compounds used for this study (in red: the functionality of the molecules vulnerable to side reactions).

Even though the McKenna reaction could be completed within a couple of hours, the rate of the reaction depends on the structure of the phosphonate ester, being especially affected by the type of substituents in the vicinity of the phosphonic group [1]. Usually the reaction is carried out for 1-3 days [26,27], in a solution of DCM or acetonitrile (ACN), although it can also be performed in neat BTMS. As far as the reaction temperature is concerned it can be performed either at room temperature, in refluxing $\mathrm{CH}_{2} \mathrm{Cl}_{2}[19,28,29]$, at higher temperatures [1,30,31], and also under microwave conditions [32-34]. At lower temperatures or shorter reaction times an incomplete transesterification was reported [35]. The use of the low-boiling $\mathrm{CH}_{2} \mathrm{Cl}_{2}$ at reflux promotes the removal of $\mathrm{EtBr}$ from the reaction mixture.

For the purpose of this study, we used the polar aprotic solvent acetonitrile due to its good solubilizing properties. The reactions were usually carried out at $35{ }^{\circ} \mathrm{C}$ for $24 \mathrm{~h}$, based on our experience with different types of phosphonate esters that indicated a more efficient transesterification reaction at this temperature. Depending on the experiment, the progress of the reaction was monitored by ${ }^{1} \mathrm{H}$ and ${ }^{31} \mathrm{P}$ NMR spectroscopy in short intervals. The complete deprotection of the phosphonate ester group in compound $\mathbf{8}$ and $\mathbf{9}$ was observed.

In all experiments, unless specified otherwise, we used commercially available BTMS, which was distilled prior to use, kept in ampules under Ar, and stored frozen in the dark. These precautions were necessary in order to eliminate the concern that the studied side reactions were due to the presence of $\mathrm{HBr}$ in the commercially available reagent.

We divided the study into five sections, each devoted to a different side reaction, summarizing the applied conditions, identifying the culprit responsible for a particular side reaction and indicating the optimal conditions, which helped to circumvent the problem.

\section{Section 1: Formation of oxazoles from propargylamides}

One of the most intriguing side reactions was observed when compounds comprising a propargyl amide group were treated with BTMS. Besides the products of addition of $\mathrm{HBr}$, we observed the formation of oxazole.

In order to study this process, we subjected an equimolar mixture of the easily available propargylamide $\mathbf{1 0}$ [22] and triethyl phosphonoacetate (8a) to BTMS (Scheme 2). Besides the target product of the McKenna reaction, phosphonic acid 14a, we also isolated a mixture of three compounds 15-17, derived from propargylamide 10, the compound, which should have remained intact under the conditions applied (Table 1, entry 1). The disappearance of the alkyne proton signals in the ${ }^{1} \mathrm{H}$ NMR spec-<smiles>C#CCNC(=O)c1ccc([N+](=O)[O-])cc1</smiles>

Scheme 2: Formation of the side products derived from 10. Conditions: An equimolar mixture of propargylamide 10 and triethyl phosphonoacetate (8a) in ACN stirred at $35^{\circ} \mathrm{C}$ in the presence of BTMS. 


\begin{tabular}{|c|c|c|c|c|c|}
\hline entry & BTMS ${ }^{a}$ & TEA & $\begin{array}{l}\text { other } \\
\text { (equiv) }\end{array}$ & $\begin{array}{l}\text { time } \\
{[\mathrm{h}]}\end{array}$ & $\begin{array}{c}\text { ratio } \\
10: 15: 16: 17\end{array}$ \\
\hline $1^{b}$ & + & - & - & 24 & 0.78:0.07:0.07:0.08 \\
\hline 2 & $+^{\mathrm{C}}$ & - & $\mathrm{Cu}$ & 24 & 0.39:0.23:0.20:0.18 \\
\hline 3 & + & - & $\begin{array}{l}\mathrm{CuBr} \\
(0.5)\end{array}$ & 48 & $0.68: 0.07: 0.09: 0.07^{d}$ \\
\hline $4^{e}$ & - & - & $\mathrm{CuBr}(0.1)$ & 48 & $1: 0: 0: 0$ \\
\hline 5 & + & - & $\begin{array}{c}\mathrm{H}_{2} \mathrm{O} \\
(2)\end{array}$ & 24 & 0:0.63:0.2:0.17 \\
\hline 6 & + & 1 equiv & - & 24 & 1:0:0:0 \\
\hline 7 & - & - & $33 \% \mathrm{HBr}$ in $\mathrm{AcOH}(1)$ & 24 & $0.67: 0.27: 0.03: 0.03$ \\
\hline 8 & - & - & TFA (1.3) & 24 & 1:0:0:0 \\
\hline
\end{tabular}

aBTMS (12 equiv) distilled and stored under Ar in a sealed ampule was used, unless otherwise stated; bthe same result was obtained when the reaction was carried out in a Schlenk apparatus, under strictly anhydrous conditions; ${ }^{c}$ commercially available reagent stabilized with copper wire was

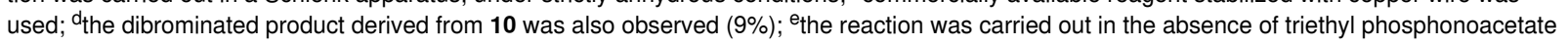
(8a).

trum $\left(\delta 2.32 \mathrm{ppm}\left(\mathrm{t},{ }^{4} J_{\mathrm{HH}}=2.6 \mathrm{~Hz}\right)\right.$ and $\delta 4.28 \mathrm{ppm}\left(\mathrm{dd},{ }^{3} J_{\mathrm{HH}}=\right.$ $\left.5.2 \mathrm{~Hz} ;{ }^{4} J_{\mathrm{HH}}=2.5 \mathrm{~Hz}\right)$ ) and, instead, the appearance of signals at $\delta 2.44 \mathrm{ppm}\left(\mathrm{d},{ }^{4} J_{\mathrm{HH}}=3.5 \mathrm{~Hz}\right)$ and $\delta 6.94 \mathrm{ppm}\left(\mathrm{q},{ }^{4} J_{\mathrm{HH}}=\right.$ $3.5 \mathrm{~Hz}$ ) indicated the formation of oxazole 15 . The presence of compound 15 was also confirmed by X-ray studies (see Figure S3 and Table S1 in Supporting Information File 1) and literature data [36]. Additionally, the formation of compounds 16 and 17 was observed, resulting from $\mathrm{HBr}$ addition to the triple bond. The presence of these products was confirmed by ${ }^{1} \mathrm{H}$ NMR analysis [signals at $\delta 5.56$ and $\delta 5.85$ ppm representing protons in $16\left(\mathrm{CBr}=\mathrm{CH}_{2}\right)$ and multiplets at $\delta 6.29$ and $6.33 \mathrm{ppm}$ representing protons in $\mathbf{1 7}(\mathrm{CH}=\mathrm{CHBr})]$.

In order to identify the factor(s) responsible for the formation of product 15, we investigated whether the copper wire, used as a stabilizer in commercially available BTMS, could induce the observed cyclization, as was reported in the literature [37]. For that purpose, we compared the reaction run using commercially available BTMS, stabilized with copper wire with that using BTMS distilled prior to use but contaminated with $\mathrm{CuBr}$ (Table 1, entries 2 and 3). In both cases the byproducts 15-17 formed. However, when propargylamide $\mathbf{1 0}$ was subjected to the reaction with $\mathrm{CuBr}$, in the absence of BTMS and phosphonoacetate, only starting material was recovered (Table 1, entry 4).

Next, we studied whether the presence of water in the reaction mixture could be responsible for the generation of the side products 15-17. It has been reported previously that hydrogen bromide generated in situ by the addition of equimolar amounts of BTMS and $\mathrm{MeOH}$ to a solution of acetylenic ethers gave $\alpha$-halovinyl ethers [38]. HBr generated in situ from BTMS and water was also used in the synthesis of $\alpha$-bromoenamides from an ynamide [39]. However, to the best of our knowledge, there are no reports on the formation of oxazoles in this manner [40].

We found that the addition of water (2 equiv) to the reaction mixture with BTMS (12 equiv, Table 1, entry 5 ) resulted in the complete conversion of substrate $\mathbf{1 0}$ into compounds 15-17 within $24 \mathrm{~h}$. In this case, over $60 \%$ of the reaction mixture constituted compound 15, while the regioisomers $\mathbf{1 6}$ and $\mathbf{1 7}$ were formed in comparable amounts. Decreasing the amount of water to 0.5 equiv or lowering the temperature (from $35^{\circ} \mathrm{C}$ to ambient temperature) decelerated the side reaction.

Unfortunately, even when carrying out the reaction under strictly anhydrous conditions (Table 1 , entry 1), a 22\% conversion of the substrate into the side products 15-17 was observed. Therefore, we repeated the reaction with triethylamine (TEA) added to the reaction mixture. These conditions appeared very promising, as no side products were formed and only the desired product 14a was obtained (Table 1, entry 6).

To address the question whether compounds $\mathbf{1 6}$ and $\mathbf{1 7}$ constitute intermediates in the reaction leading to $\mathbf{1 5}$, we isolated the mixture of $\mathbf{1 6}$ and 17. The exposure of this mixture to BTMS, in the presence or absence of water, left them unaffected, indicating that the formation of the side products 15 and 16,17 proceeded through independent pathways.

Since the known procedures for the syntheses of oxazoles are rather harsh and usually involve higher temperature $\left[\mathrm{Pd}(\mathrm{OAc})_{2}\right.$, toluene, $\mathrm{AcOH}, 100{ }^{\circ} \mathrm{C}, 24 \mathrm{~h}$ [41] and/or the presence of Lewis acids $\left(\mathrm{FeCl}_{3}, \mathrm{ACN}\left(24 \mathrm{~h}, 80^{\circ} \mathrm{C}\right)\right.$ or 1,2-DCE $\left(2 \mathrm{~h}, 80^{\circ} \mathrm{C}\right)$, DCM 
$\left(24 \mathrm{~h}, 45^{\circ} \mathrm{C}\right)$ [40]], we envisioned that the present method could be of synthetic value, if we were able to redirect the reaction towards the exclusive formation of oxazole 15. However, our attempts at optimizing the conditions towards product $\mathbf{1 5}$ only led to partial success (see Table S2 in Supporting Information File 1) and the highest conversion of $\mathbf{1 0}$ into $\mathbf{1 5}$ was $63 \%$. Still, even though the transformation was not fully selective, the pure oxazole 15 could be easily isolated from the reaction mixture in good yield ( $>50 \%$ ). The products $\mathbf{1 5 - 1 7}$ did also form when compound $\mathbf{1 0}$ was treated with $\mathrm{HBr}$ in $\mathrm{AcOH}$ (Table 1, entry 7). However, all attempts at eliminating the formation of the addition products $\mathbf{1 6}$ and $\mathbf{1 7}$, by using other acids (e.g., TFA, $\mathrm{AcOH}, \mathrm{HCl}$, or $\mathrm{CF}_{3} \mathrm{SO}_{3} \mathrm{H}$ ) failed and only substrate $\mathbf{1 0}$ was recovered (see Table 1, entry 8 , and Supporting Information File 1, Table S2).

\section{Section 2: Addition of $\mathrm{HBr}$ to the double bond}

$\mathrm{HBr}$ might form upon careless storage and/or use of BTMS, which exposes it to traces of water. As mentioned in the previous section, compounds having multiple bonds could undergo an addition reaction upon exposure to $\mathrm{HBr}$ [42]. We studied this problem using ${ }^{1} \mathrm{H}$ NMR spectroscopy with the model acrylamide $\mathbf{1 1}$ (Scheme 3), representing a Michael acceptor, as such is currently popular in the development of covalent inhibitors [43]. The reaction was carried out in the presence of 12 equiv BTMS at $35^{\circ} \mathrm{C}$. The disappearance of the signals originating from the vinyl protons (multiplets at $\delta$ 5.56-5.66 and 5.95-6.10 ppm) and the appearance of the signals corresponding to the $\mathrm{CH}_{2} \mathrm{CH}_{2} \mathrm{Br}$ group in $\mathbf{1 8}$ (multiplets at $\delta 2.69$ and $3.61 \mathrm{ppm}$ ) were taken as indicators of the side reaction. We found that the product of $\mathrm{HBr}$ addition formed only upon the intentional addition of water, due to the formation of $\mathrm{HBr}$ from BTMS, while under standard anhydrous conditions no side product was observed. The reaction was stoichiometric and in the case of adding 0.5 equiv of water, the conversion into 18 reached $47 \%$ within $24 \mathrm{~h}$ at $35^{\circ} \mathrm{C}$. The addition of TEA ( 1 equiv) protected compound 11 against $\mathrm{HBr}$ addition, as we have observed in the experiment with 0.5 equiv of water and 1 equiv of TEA.

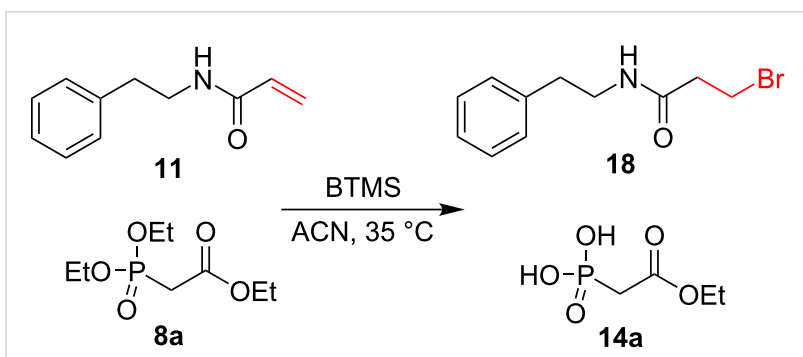

Scheme 3: Addition of $\mathrm{HBr}$ to compound 11.

\section{Section 3: N-Alkylation}

As reported in the original paper [1], the McKenna reaction required up to $2 \mathrm{~h}$ at room temperature for simple phosphonates. However, depending on the structure of the phosphonate, longer reaction times are required, and the reaction is commonly carried out overnight [26,27]. However, during the first step of the McKenna reaction, alkyl bromide is formed (Scheme 1) representing an alkylating agent, which upon prolonged reaction time, may lead to side product formation. In order to study this process, we chose phosphonate analogs $\mathbf{9 a}-\mathbf{d}$ and acryl amide $\mathbf{1 2}$ as the model compounds. While in the case of compounds 9a-d the source of the alkyl bromide, i.e., a dialkyl phosphonate group already was part of the compound structures, the reactions with compound $\mathbf{1 2}$ were performed in the presence of trialkyl phosphonoacetates (Scheme 4 and Scheme 5).

As expected, our studies using phosphonates 9a,b showed that as the concentration of ethyl bromide increases (Scheme 1), the formation of the $N$-alkylated product 20 was observed (Scheme 4), for compound 9a as well as for the $\alpha$-fluorinated analog 9b (7-10\% within $24 \mathrm{~h}$, at $35{ }^{\circ} \mathrm{C}$, monitored by ${ }^{31}$ P NMR spectroscopy; see Figure S13 in Supporting Information File 1).

When performing the reaction of $9 \mathbf{b}$ with BTMS under a gentle flow of inert gas (in order to remove the volatile ethyl bromide), we observed a slight decrease in the formation of the $\mathrm{N}$-alky-

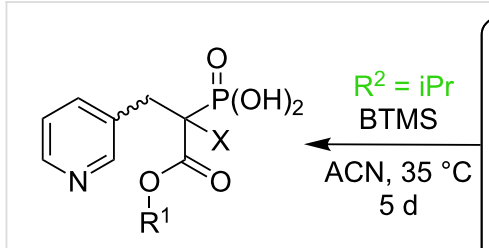

19a: $R^{1}=E t, X=H$

19b: $R^{1}=E t, X=F$<smiles>[R]OC(=O)C([X])(Cc1cccnc1)[P+]([R])=O</smiles>

9a: $R^{1}=E t, R^{2}=E t, X=H$ 9b: $R^{1}=E t, R^{2}=E t, X=F$ 9c: $R^{1}=E t, R^{2}=i P r, X=H$ 9d: $R^{1}=E t, R^{2}=i P r, X=F$

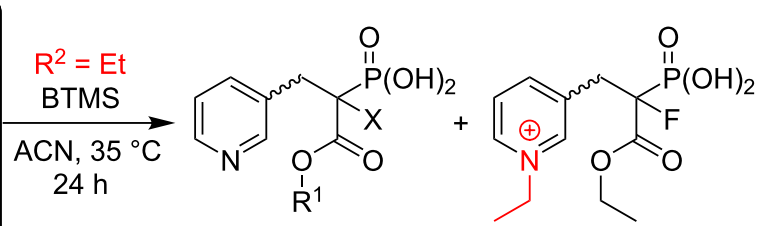

19a: $R^{1}=E t, X=H$ 19b: $R^{1}=E t, X=F$
20 

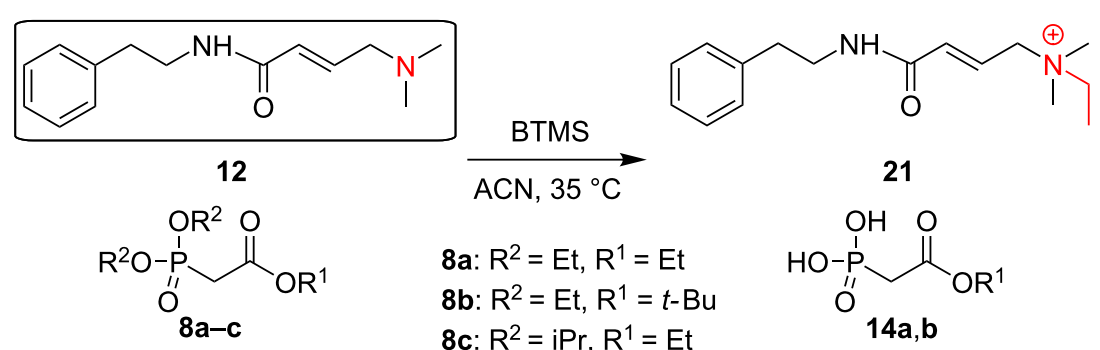

$$
\begin{aligned}
& \text { 8a: } R^{2}=E t, R^{1}=E t \\
& \text { 8b: } R^{2}=E t, R^{1}=t-B u \\
& \text { 8c: } R^{2}=i P r, R^{1}=E t
\end{aligned}
$$<smiles>[R]OC(=O)CP(=O)(O)O</smiles>

Scheme 5: N-Alkylation of 12

lated product 20 (from $7-10 \%$ to $5 \%$ ). However, the flow of the gas needed to be gently controlled to avoid BTMS removal from the reaction mixture.

We encountered a different situation for compound $\mathbf{1 2}$. This substrate underwent $N$-alkylation under the McKenna reaction conditions only in the presence of $\mathrm{Et}_{3} \mathrm{~N}$, a commonly used additive for the protection of unsaturated compounds, such as compound 12 towards $\mathrm{HBr}$ addition to the double bond. Within $24 \mathrm{~h}$ we observed $\approx 90 \%$ conversion into the aminium salt 21 . Decreasing the amount of $\mathrm{Et}_{3} \mathrm{~N}$, also led to a decrease in the amount of the $N$-alkylated side product (reaching zero when no $\mathrm{Et}_{3} \mathrm{~N}$ was added). This indicated that excess $\mathrm{Et}_{3} \mathrm{~N}$ makes compound $\mathbf{1 2}$ more susceptible to $N$-alkylation. The reason for this observation might be the significantly higher basicity of $\mathrm{Et}_{3} \mathrm{~N}$ ( $\mathrm{p} K_{\mathrm{a}} 10.65$ ) compared to $\mathbf{1 2}$, as approximated based on the $\mathrm{p} K_{\mathrm{a}} \mathrm{s}$ of representative amines resembling the structure of compound 12, $\mathrm{Me}_{3} \mathrm{~N}\left(\mathrm{p} K_{\mathrm{a}}\right.$ 9.76) and allyldimethylamine $\left(\mathrm{p} K_{\mathrm{a}}\right.$ 8.72), respectively [44]. This effect was reinforced by the higher nucleophilicity of the nitrogen atom in $\mathbf{1 2}$ compared with $\mathrm{Et}_{3} \mathrm{~N}$, as we deduced by comparison of model tertiary amines: $\mathrm{Me}_{3} \mathrm{~N}$ (in $\mathrm{MeCN}$ : N 23.05, $\mathrm{s}_{\mathrm{N}}$ 0.45) and $\mathrm{Et}_{3} \mathrm{~N}$ (in $\mathrm{MeCN}$ : $\mathrm{N} 17.10, \mathrm{~s}_{\mathrm{N}}$ $0.52)[45,46]$. On the other hand, the lower nucleophilicity of pyridine compared with the tertiary alkylamine present in compound $12[45,46]$ may be responsible for the lower vulnerability of 9 towards alkylation.

Another approach to circumvent the formation of $N$-alkylation products was based on the use of the more sterically hindered diisopropyl phosphonate ester instead of the diethyl analogs. Even though the silylation step required longer times in case of the diisopropyl phosphonate ester [1], which may promote the formation of side products, no $\mathrm{N}$-alkylated product was observed, neither for diisopropyl phosphonates $\mathbf{9 c , d}$ (even during 13 days), nor for the reaction of compound 12 in the presence of diisopropyl phosphonoacetate 8c, even with TEA (10 equiv) added (Table 2, entry 4). However, it could not be excluded that this positive outcome would be observed for dimethyl phosphonate esters, due to the low boiling point of methyl bromide $\left(\approx 4{ }^{\circ} \mathrm{C}\right)$, and therefore its easy removal from the reaction mixture.

Table 2: Investigation of the reaction between compound 12, phosphonoacetates 8 and BTMS. ${ }^{a}$

$\begin{array}{llllr}\text { entry } & R^{1} & R^{2} & \text { TEA ratio }\end{array}$

\begin{tabular}{ccccc} 
& & & & $\mathbf{1 2 : 2 1}$ \\
\hline 1 & $t$-Bu & Et & 6 & $0.18: 0.82$ \\
2 & $t$-Bu & Et & 3 & $0.58: 0.42$ \\
3 & $t$-Bu & Et & - & $1: 0$ \\
4 & $\mathrm{Et}$ & $\mathrm{iPr}$ & 10 & $1: 0$ \\
\hline
\end{tabular}

aReactions carried out for $24 \mathrm{~h}$ at $35^{\circ} \mathrm{C}$ in the presence of the appropriate phosphonoacetate (see Scheme 5 ) using distilled BTMS.

\section{Section 4: Exchange of chloride for bromide}

BTMS is known to act as brominating agent for various functional groups, such as alcohols $[47,48]$, three- and four-membered cyclic ethers [49], and anomeric glycosyl acetates [50]. However, to the best of our knowledge, there were no reports on using BTMS for the nucleophilic substitution of alkyl chlorides. A similar exchange reaction was reported only for 2-chloropyridines [51], and required harsh reaction conditions, such as heating at $90-100{ }^{\circ} \mathrm{C}$ for $100 \mathrm{~h}$.

In this study we investigated the susceptibility of 2-chloro- $N$ phenethylacetamide (13), towards halogen exchange mediated by BTMS (Scheme 6). The reaction progress was monitored by

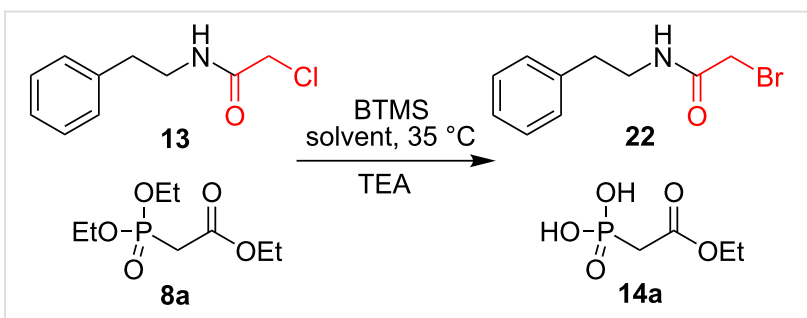

Scheme 6: Exchange of the chlorine substituent with bromine in 2-chloro- $N$-phenethylacetamide (13) under McKenna reaction conditions. 
${ }^{1} \mathrm{H}$ NMR spectroscopy monitoring the signals of the methylene groups $\mathrm{C}(\mathrm{O}) \mathrm{CH}_{2} \mathrm{Cl}$ in $\mathbf{1 3}$ vs $\mathrm{C}(\mathrm{O}) \mathrm{CH}_{2} \mathrm{Br}$ in the product 22 (see Figure S16 in Supporting Information File 1). Further, we confirmed the identity of brominated product $\mathbf{2 2}$ by mass spectrometry.

Under these conditions compound $\mathbf{1 3}$ underwent an almost complete exchange of chlorine for bromine in the presence of BTMS in $\mathrm{MeCN}$ at $35{ }^{\circ} \mathrm{C}$ within $3 \mathrm{~h}$ (Table 3, entry 1). Changing the solvent to the non-polar aprotic solvent, $\mathrm{CDCl}_{3}$ (Table 3, entry 2, 42\% conversion after $3 \mathrm{~h}$ ) as well as lowering the temperature (Table 3, entry $3, \mathrm{rt}, \mathrm{CDCl}_{3}$, after $24 \mathrm{~h} 50 \%$ conversion into 22) slowed down the reaction. When TEA was added to the mixture, the halogen-exchange reaction slightly decreased (Table 3, entries 4 and 5). Remarkably, when performing the reaction without phosphonate added, we isolated only side product 22, demonstrating that the McKenna reaction and the substitution of chloride were two independent processes (Table 3, entry 6). Based on these results we summarized, that the $\alpha$-chloroacetamide is susceptible to reaction with BTMS, and underwent exchange of the chlorine substituent for bromine. This reaction can be partially circumvented by using nonpolar solvents, amines and lower temperatures.

\begin{tabular}{|c|c|c|c|c|c|}
\hline entry & solvent & TEA & $P C^{b}$ & $\begin{array}{c}\text { time } \\
{[\mathrm{h}]}\end{array}$ & $\begin{array}{c}\text { ratio } \\
13: 22\end{array}$ \\
\hline 1 & ACN & - & + & $\begin{array}{c}1 \\
3 \\
24\end{array}$ & $\begin{array}{c}0.15: 0.85 \\
0.02: 0.98 \\
0: 1\end{array}$ \\
\hline 2 & $\mathrm{CDCl}_{3}$ & - & + & $\begin{array}{c}3 \\
24\end{array}$ & $\begin{array}{c}0.58: 0.42 \\
0: 1\end{array}$ \\
\hline 3 & $\mathrm{CDCl}_{3}$ & - & - & $24(r t)$ & 0.5:0.5 \\
\hline 4 & $\mathrm{ACN}$ & 1 & + & 3 & $0.57: 0.43$ \\
\hline 5 & $\mathrm{CDCl}_{3}$ & 1 & + & 3 & $0.64: 0.36$ \\
\hline 6 & ACN & - & - & 24 & $0: 1$ \\
\hline
\end{tabular}

aThe reaction was carried out with distilled BTMS (6 equiv) at $35^{\circ} \mathrm{C}$, except for entry 3 , where the reaction was carried out at rt; ${ }^{\mathrm{b} P C}$ : trialkyl phosphonocarboxylate $\mathbf{8 a}$

\section{Section 5: Cleavage of the tert-butyl carboxyester group}

BTMS is known for its chemoselectivity and cleaves phosphonate esters, without affecting carboxyester groups. However, the formation of phosphonic acids in the solvolysis step of the Mc Kenna reaction could lead to the cleavage of acid-labile groups [52,53]. In order to prevent this reaction, the solvolysis step commonly is performed in buffered solutions [53].

In this study, we took a closer look at the reactivity upon exposure to BTMS of two types of carboxyester groups, the acid- labile tert-butyl and the relatively stable ethyl esters. For this we chose triethyl phosphonoacetate $(\mathbf{8 a})$, tert-butyl phosphonoacetate (8b) and its pyridine-3-ylmethyl analogs $\mathbf{9 a , e}$ as the model compounds.

The reaction progress was monitored by ${ }^{31} \mathrm{P}$ and ${ }^{1} \mathrm{H}$ NMR spectroscopy. The cleavage of the carboxyester group during the first step of the McKenna reaction, was observed as an upfield signal in the ${ }^{31} \mathrm{P}$ NMR spectrum (by $0.5-1 \mathrm{ppm}$ ), and changes of multiplet signals in the ${ }^{1} \mathrm{H}$ NMR spectrum (in case of tertbutyl carboxyesters as a decrease in the signal stemming from the $t$-Bu ester group ( $\delta 1.46 \mathrm{ppm})$ and the appearance of residual signals from isobutylene: $\delta 1.71(\mathrm{t})$ and 4.65 (heptet) ppm; multiplication of signals representing methylene group, bridging carboxylate and phosphonate groups (see Supporting Information File 1, Figures S20-S22). Afterwards, the samples were evaporated and subjected to solvolysis with $\mathrm{CD}_{3} \mathrm{OD} / \mathrm{D}_{2} \mathrm{O}$ (Table 4, last column).

As reported previously [2], when applying BTMS to triethyl phosphonoacetate (8a), we did not observe a cleavage of the carboethoxy group during the silylation step (Table 4, entry 1). However, the result of the subsequent solvolysis of the thus formed trimethylsilyl ester $\mathbf{2 3}$, depended on the conditions applied. The exposure of $\mathbf{2 3}$ to acetone or methanol, gave only the expected product $\mathbf{2 4}$ (up to $24 \mathrm{~h}$ ). However, when a mixture of methanol and water $(20: 1, \mathrm{v} / \mathrm{v})$ was used, traces $(2 \%)$ of the fully hydrolyzed product 25 were detected, but only after $24 \mathrm{~h}$ (Table 4, entry 1), while the solvolysis usually takes a few minutes.

Trying to simulate the conditions of a not appropriately carried out McKenna reaction, i.e., BTMS not thoroughly evaporated before solvolysis, we added BTMS at the solvolysis stage to the mixture of methanol and water $(40: 1, \mathrm{v} / \mathrm{v})$. In this case we observed a partial ethyl ester cleavage (up to $7 \%$ ), and its transesterification into methyl ester $\mathbf{2 6}$ (up to $30 \%$ within $18 \mathrm{~h}$, Table 4, entry 2).

Next we turned to the vulnerability of the tert-butyl ester group to BTMS. While iodotrimethylsilane is known for its capability to cleaving carboxyester groups [12,54], with tert-butyl and benzyl esters being more susceptible than methyl or ethyl esters, no such reaction was reported in the presence of BTMS. To our surprise we observed a partial cleavage of the tert-butyl ester group present in phosphonoacetate $\mathbf{8 b}$ already at the silylation step (30\% within $1 \mathrm{~h} ; 100 \%$ after $24 \mathrm{~h}$; Table 4, entry 3$)$. In order to exclude the possibility that this reaction was caused by the presence of trace amounts of $\mathrm{HBr}$, we tested $\mathrm{Et}_{3} \mathrm{~N}$ (1 equiv) or pyridine ( 1 or 2 equiv) as scavengers. Although the reaction slowed down, still a significant cleavage of the tert-butyl ester 


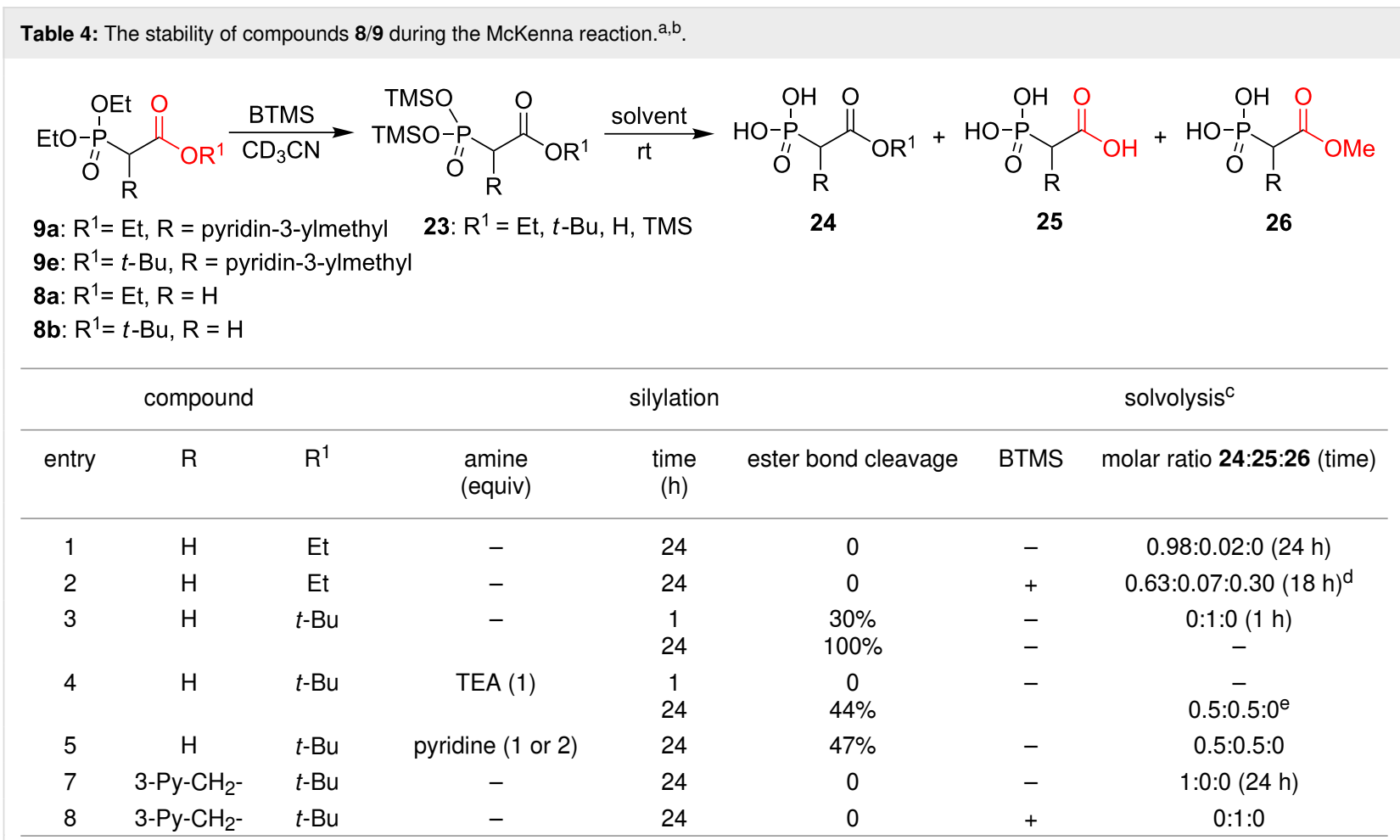

aReaction carried out in $\mathrm{CD}_{3} \mathrm{CN}$ at rt with 12 equiv BTMS (distilled), unless defined otherwise; bfor analogs $\mathrm{R}=\mathrm{H}$, the McKenna reaction completed within $1 \mathrm{~h}$; for analogs $\mathrm{R}=$ pyridin-3-ylmethyl, the McKenna reaction was completed within $2 \mathrm{~h}$; ${ }^{c}$ the experiment was run on the same sample as the one used for the BTMS studies. For this, the sample was evaporated and directly subjected to solvolysis with $\mathrm{MeOD} / \mathrm{D}_{2} \mathrm{O} 20: 1$ ( $\mathrm{v} / \mathrm{v}$ ) for $5-10$ minutes,

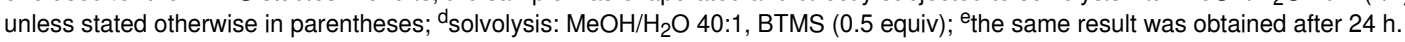

bond was detected within $24 \mathrm{~h}$ (Table 4, entries 4 and 5). This observation might imply that this reaction was similar to the one between carboxyesters and ITMS, and proceeded via a silylated ester bromide salt intermediate [12,54].

In a further experiment we subjected tert-butyl ester 9e to BTMS action. This model compound contained a pyridine ring embedded in the structure and in this case no cleavage of the tert-butyl group was observed (Table 4, entry 7). This result was opposite to the one obtained for tert-butyl phosphonoacetate $\mathbf{8 b}$ in the presence of pyridine (Table 4, entry 5). At this point the role of pyridine, either added to the mixture or embedded within the carboxyester molecules, remained unclear.

\section{Conclusion}

The McKenna reaction is one of the most robust methods for the mild deprotection of organophosphorus esters. However, the benefits of this reaction are sometimes overshadowed by side reactions taking place when polyfunctional organophosphorus compounds are involved. Here, we evaluated experiments that did not work, the so called "dark data" [21], and we demonstrated that contrary to common belief: 1) BTMS itself led to the cleavage of tert-butyl carboxyesters, and 2) amines, a com- monly used standard additives in the McKenna reaction were not generally safe and may promoted side reactions in the presence of certain functional groups. Besides that, we discovered two new applications of BTMS, providing new mild methods for the synthesis of oxazoles and an $\alpha$-bromoacetamide. Even though the former synthesis was not completely chemoselective, the pure oxazoles could be easily isolated in good yields, and the proposed procedure constitutes an interesting alternative to existing methods, which usually require harsh conditions.

\section{Experimental}

Knowing the sensitivity of the McKenna reaction to water and oxygen, all equipment and reagents were dried prior to use and the reactions were run under an inert argon atmosphere, unless specified otherwise. $\mathrm{CH}_{3} \mathrm{CN} / \mathrm{CD}_{3} \mathrm{CN}$ and $\mathrm{CHCl}_{3} / \mathrm{CDCl}_{3}$ were dried using activated $3 \AA$ and $4 \AA$ molecular sieves. In all experiments, unless specified otherwise, we used commercial BTMS, which was distilled and placed in ampules under Ar, and stored frozen in the dark until use. Triethylamine and pyridine were distilled and stored over sodium hydroxide, All reagents, including synthesized and commercially available phosphonoacetates were dried with appropriate drying agents and under high vacuum. In most cases, the reaction progress, of 
both, the silylation step using BTMS as well as the solvolysis step, were monitored by ${ }^{1} \mathrm{H}$ and ${ }^{31} \mathrm{P}$ NMR spectroscopy, using deuterated solvents, $\mathrm{CD}_{3} \mathrm{CN}, \mathrm{CDCl}_{3}, \mathrm{CD}_{3} \mathrm{OD}$, or $\mathrm{D}_{2} \mathrm{O}$. The progress of the McKenna reaction can easily be monitored by ${ }^{31} \mathrm{P}$ NMR spectroscopy, where the exchange of each alkyl for trimethylsilyl group in the phosphonate involves $\mathrm{a} \approx 8-10 \mathrm{ppm}$ upfield shift of signals in the spectrum. The side products were isolated and their structures confirmed by NMR spectroscopy and HRMS. Mass spectra were recorded in the positive ion mode with an Agilent 6220 mass spectrometer coupled with an Agilent 1200 series HPLC. NMR spectra were measured at 250.13 or $700 \mathrm{MHz}$ for ${ }^{1} \mathrm{H} \mathrm{NMR}, 62.90$ or $170 \mathrm{MHz}$ for ${ }^{13} \mathrm{C}$ NMR, and 283 or $101.30 \mathrm{MHz}$ for ${ }^{31} \mathrm{P}$ NMR on a Bruker Avance DPX 250 or a Bruker Avance II Plus 700 spectrometer, respectively.

\section{General procedures for the McKenna reaction (recommended)}

All reactions were run under an Ar atmosphere, using dry equipment, dried solvents and reagents. In a dried roundbottomed flask equipped with a septum, the appropriate substrate was placed (1 equiv) and dissolved in $\mathrm{ACN}$ or $\mathrm{CHCl}_{3}$ $(50 \mathrm{mg} / 1.5 \mathrm{~mL})$. Then, TEA (1 equiv, as specified in the text the addition of TEA was required only in certain cases) was added, followed by BTMS (6-8 equiv). The septum was exchanged by a fitted glass stopper and additionally secured with parafilm. The flask was placed in a sand bath at $36{ }^{\circ} \mathrm{C}$ for $24 \mathrm{~h}$. Afterwards, the solution was evaporated and the mixture subjected to solvolysis, using either acetone, ethanol or methanol/water $(20: 1, \mathrm{v} / \mathrm{v})$.

The isolation of phosphonic acids as the main products of the McKenna reaction was not the topic of this investigation, and most model substrates that were used in the study did not contain organophosphorus ester/acid. If required (compounds 20 and 21), the product was purified by HPLC. Additionally, the free phosphonic acid could be easily removed from the reaction mixture by washing with aqueous sodium carbonate solution.

\section{Supporting Information}

\section{Supporting Information File 1}

Synthesis of starting materials, copies of ${ }^{31} \mathrm{P}$ NMR,

${ }^{1} \mathrm{H}$ NMR, and ${ }^{13} \mathrm{C}$ NMR spectra for all new compounds and selected NMR spectra illustrating the formation of the side products.

[https://www.beilstein-journals.org/bjoc/content/ supplementary/1860-5397-16-119-S1.pdf]

\section{Acknowledgements}

We thank Dr. Marek Domin (Boston College) for HRMS of side products. We thank Dr. Barbara Pacholczyk-Sienicka and Mr Grzegorz Ciepielowski for carrying out NMR experiments. We thank Prof. Tadeusz Gajda (Lodz University of Technology, Poland) and Dr. Agnieszka Dybała-Defratyka (Lodz University of Technology, Poland) for reading the manuscript and for helpful suggestions on how to improve the text.

\section{Funding}

This work was financially supported by the National Science Centre, Poland (Sonata Bis 2014/14/E/ST5/00491, Preludium 2016/23/N/ST5/03230).

\section{ORCID ${ }^{\circledR} \mathrm{iDs}$}

Katarzyna Justyna - https://orcid.org/0000-0003-4630-1581 Joanna Małolepsza - https://orcid.org/0000-0002-2748-6798 Damian Kusy - https://orcid.org/0000-0002-0643-3478 Waldemar Maniukiewicz - https://orcid.org/0000-0001-6094-0748 Katarzyna M. Błażewska - https://orcid.org/0000-0002-1218-7111

\section{References}

1. McKenna, C. E.; Higa, M. T.; Cheung, N. H.; McKenna, M.-C. Tetrahedron Lett. 1977, 18, 155-158. doi:10.1016/s0040-4039(01)92575-4

2. McKenna, C. E.; Schmidhuser, J. J. Chem. Soc., Chem. Commun. 1979, 739. doi:10.1039/c39790000739

3. Westheimer, F. H. Science 1987, 235, 1173-1178. doi: $10.1126 /$ science. 2434996

4. Jessen, H. J. Synlett 2018, 29, 699-713. doi:10.1055/s-0036-1591922

5. Ebetino, F. H.; Hogan, A.-M. L.; Sun, S.; Tsoumpra, M. K.; Duan, X.; Triffitt, J. T.; Kwaasi, A. A.; Dunford, J. E.; Barnett, B. L.; Oppermann, U.; Lundy, M. W.; Boyde, A.; Kashemirov, B. A.; McKenna, C. E.; Russell, R. G. G. Bone 2011, 49, 20-33. doi:10.1016/j.bone.2011.03.774

6. Meier, C.; Jessen, H. J.; Schulz, T.; Weinschenk, L.; Pertenbreiter, F.; Balzarini, J. Curr. Med. Chem. 2015, 22, 3933-3950. doi:10.2174/0929867322666150825163119

7. Joachimiak, Ł.; Błażewska, K. M. J. Med. Chem. 2018, 61, 8536-8562. doi:10.1021/acs.jmedchem.8b00249

8. Qiu, J.; Hameau, A.; Shi, X.; Mignani, S.; Majoral, J.-P.; Caminade, A.-M. ChemPlusChem 2019, 84, 1070-1080. doi:10.1002/cplu.201900337

9. Błażewska, K. M. J. Org. Chem. 2014, 79, 408-412. doi:10.1021/jo4021612

10. Martinelli, M. J.; Pollack, S. R. Bromotrimethylsilane. Encyclopedia of Reagents for Organic Synthesis; John Wiley \& Sons, Ltd: Chichester, United Kingdom, 2006; pp 92-100. doi:10.1002/047084289x.rb327.pub2

11. Zygmunt, J.; Kafarski, P.; Mastalerz, P. Synthesis 1978, 609-612. doi:10.1055/s-1978-24832

12. Olah, G. A.; Narang, S. C. Tetrahedron 1982, 38, 2225-2277. doi:10.1016/0040-4020(82)87002-6

13. Rabinowitz, R. J. Org. Chem. 1963, 28, 2975-2978. doi:10.1021/jo01046a008 
14. Morris, A. D.; Cordi, A. A. Synth. Commun. 1997, 27, 1259-1266. doi:10.1080/00397919708003363

15. Grison, C.; Coutrot, P.; Comoy, C.; Balas, L.; Joliez, S.; Lavecchia, G.; Oliger, P.; Penverne, B.; Serre, V.; Hervé, G. Eur. J. Med. Chem. 2004, 39, 333-344. doi:10.1016/j.ejmech.2004.01.006

16. Krečmerová, M.; Dračínský, M.; Hocková, D.; Holý, A.; Keough, D. T.; Guddat, L. W. Bioorg. Med. Chem. 2012, 20, 1222-1230. doi:10.1016/j.bmc.2011.12.034

17. Richter, F.; Weichmann, H. J. Organomet. Chem. 1994, 466, 77-87. doi:10.1016/0022-328x(94)88031-x

18. Chen, W.; Flavin, M. T.; Filler, R.; Xu, Z.-Q. J. Chem. Soc., Perkin Trans. 1 1998, 3979-3988. doi:10.1039/a805929b

19. Hladezuk, I.; Chastagner, V.; Collins, S. G.; Plunkett, S. J.; Ford, A.; Debarge, S.; Maguire, A. R. Tetrahedron 2012, 68, 1894-1909. doi:10.1016/j.tet.2011.12.077

20. Debarge, S.; Balzarini, J.; Maguire, A. R. J. Org. Chem. 2011, 76, 105-126. doi:10.1021/jo101738e

21. Björnmalm, M.; Caruso, F. Angew. Chem., Int. Ed. 2018, 57, 1122-1123. doi:10.1002/anie.201710493

22. Jiang, C.-s.; Wang, X.-m.; Zhang, S.-q.; Meng, L.-s.; Zhu, W.-h.; Xu, J.; Lu, S.-m. Bioorg. Med. Chem. 2015, 23, 6510-6519. doi:10.1016/j.bmc.2015.08.007

23. Cumine, F.; Zhou, S.; Tuttle, T.; Murphy, J. A. Org. Biomol. Chem. 2017, 15, 3324-3336. doi:10.1039/c7ob00036g

24. Bateman, L. A.; Nguyen, T. B.; Roberts, A. M.; Miyamoto, D. K.; Ku, W.-M.; Huffman, T. R.; Petri, Y.; Heslin, M. J.; Contreras, C. M.; Skibola, C. F.; Olzmann, J. A.; Nomura, D. K. Chem. Commun. 2017, 53, 7234-7237. doi:10.1039/c7cc01480e

25. Kaźmierczak, A.; Kusy, D.; Niinivehmas, S. P.; Gmach, J.; Joachimiak, Ł.; Pentikäinen, O. T.; Gendaszewska-Darmach, E.; Błażewska, K. M. J. Med. Chem. 2017, 60, 8781-8800. doi:10.1021/acs.jmedchem.7b00811

26. Riley, A. M.; Wang, H.; Shears, S. B.; Potter, B. V. L. MedChemComm 2019, 10, 1165-1172. doi:10.1039/c9md00163h

27. Chamberlain, B. T.; Upton, T. G.; Kashemirov, B. A.; McKenna, C. E. J. Org. Chem. 2011, 76, 5132-5136. doi:10.1021/jo200045a

28. Wąsek, K.; Kędzia, J.; Krawczyk, H. Tetrahedron: Asymmetry 2010, 21, 2081-2086. doi:10.1016/j.tetasy.2010.07.017

29. Akgun, B.; Savci, E.; Avci, D. J. Polym. Sci., Part A: Polym. Chem. 2012, 50, 801-810. doi:10.1002/pola.25835

30. Sakamoto, A.; Matsuo, Y.; Matsuo, K.; Nakamura, E. Chem. - Asian J. 2009, 4, 1208-1212. doi:10.1002/asia.200900155

31. Fuhrmann, J.; Subramanian, V.; Thompson, P. R. Angew. Chem., Int. Ed. 2015, 54, 14715-14718. doi:10.1002/anie.201506737

32. Mullins, N. D.; Maguire, N. M.; Ford, A.; Das, K.; Arnold, E.; Balzarini, J.; Maguire, A. R. Org. Biomol. Chem. 2016, 14, 2454-2465. doi:10.1039/c5ob02507a

33. Lodewyk, M. W.; Lui, V. G.; Tantillo, D. J. Tetrahedron Lett. 2010, 51, 170-173. doi:10.1016/j.tetlet.2009.10.119

34. Seamon, K. J.; Hansen, E. C.; Kadina, A. P.; Kashemirov, B. A.; McKenna, C. E.; Bumpus, N. N.; Stivers, J. T. J. Am. Chem. Soc. 2014, 136, 9822-9825. doi:10.1021/ja5035717

35. Thirumalairajan, S.; Mahaney, B.; Bearne, S. L. Chem. Commun. 2010, 46, 3158-3160. doi:10.1039/b926894d

36. Senadi, G. C.; Hu, W.-P.; Hsiao, J.-S.; Vandavasi, J. K.; Chen, C.-Y.; Wang, J.-J. Org. Lett. 2012, 14, 4478-4481. doi:10.1021/ol301980g

37. Lauder, K.; Toscani, A.; Scalacci, N.; Castagnolo, D. Chem. Rev. 2017, 117, 14091-14200. doi:10.1021/acs.chemrev.7b00343
38. Yu, W.; Jin, Z. J. Am. Chem. Soc. 2000, 122, 9840-9841. doi:10.1021/ja000903s

39. Sato, A. H.; Ohashi, K.; Iwasawa, T. Tetrahedron Lett. 2013, 54, 1309-1311. doi:10.1016/j.tetlet.2012.12.101

40. Hu, Y.; Xin, X.; Wan, B. Tetrahedron Lett. 2015, 56, 32-52. doi:10.1016/j.tetlet.2014.11.061

41. Mali, J. K.; Takale, B. S.; Telvekar, V. N. RSC Adv. 2017, 7, 2231-2235. doi:10.1039/c6ra25857c

42. Koehler, J.; Kuehne, A. J. C.; Piermattei, A.; Quu, J.; Keul, H. A.; Dirks, T.; Keul, H.; Moeller, M. J. Mater. Chem. B 2015, 3, 804-813. doi:10.1039/c4tb01719f

43. Jackson, P. A.; Widen, J. C.; Harki, D. A.; Brummond, K. M. J. Med. Chem. 2017, 60, 839-885. doi:10.1021/acs.jmedchem.6b00788

44. Hall, H. K., Jr. J. Am. Chem. Soc. 1957, 79, 5441-5444. doi:10.1021/ja01577a030

45. Byrne, P. A.; Kobayashi, S.; Breugst, M.; Laub, H.; Mayr, H. J. Phys. Org. Chem. 2016, 29, 759-767. doi:10.1002/poc.3580

46. Ammer, J.; Baidya, M.; Kobayashi, S.; Mayr, H. J. Phys. Org. Chem. 2010, 23, 1029-1035. doi:10.1002/poc.1707

47. Jung, M. E.; Hatfield, G. L. Tetrahedron Lett. 1978, 19, 4483-4486. doi:10.1016/s0040-4039(01)95258-x

48. Sedghizadeh, P. P.; Sun, S.; Junka, A. F.; Richard, E.; Sadrerafi, K.; Mahabady, S.; Bakhshalian, N.; Tjokro, N.; Bartoszewicz, M.; Oleksy, M.; Szymczyk, P.; Lundy, M. W.; Neighbors, J. D.; Russell, R. G. G.; McKenna, C. E.; Ebetino, F. H. J. Med. Chem. 2017, 60, 2326-2343. doi:10.1021/acs.jmedchem.6b01615

49. Kricheldorf, H. R.; Mörber, G.; Regel, W. Synthesis 1981, 383-384. doi:10.1055/s-1981-29460

50. Gillard, J. W.; Israel, M. Tetrahedron Lett. 1981, 22, 513-516. doi:10.1016/s0040-4039(01)90142-x

51. Schlosser, M.; Cottet, F. Eur. J. Org. Chem. 2002, 4181-4184. doi:10.1002/1099-0690(200212)2002:24<4181::aid-ejoc4181>3.0.co;2$\mathrm{m}$

52. Marma, M. S.; Khawli, L. A.; Harutunian, V.; Kashemirov, B. A.; McKenna, C. E. J. Fluorine Chem. 2005, 126, 1467-1475. doi:10.1016/j.jluchem.2005.04.002

53. Gross, H.; Keitel, I.; Costisella, B.; McKenna, C. E. Phosphorus, Sulfur Silicon Relat. Elem. 1991, 61, 177-181. doi:10.1080/10426509108036796

54. Jung, M. F.; Lyster, M. A. J. Am. Chem. Soc. 1977, 99, 968-969. doi:10.1021/ja00445a062 


\section{License and Terms}

This is an Open Access article under the terms of the Creative Commons Attribution License (http://creativecommons.org/licenses/by/4.0). Please note that the reuse, redistribution and reproduction in particular requires that the authors and source are credited.

The license is subject to the Beilstein Journal of Organic Chemistry terms and conditions:

(https://www.beilstein-journals.org/bjoc)

The definitive version of this article is the electronic one which can be found at:

$\underline{\text { doi:10.3762/bjoc. } 16.119}$ 